\title{
AQUAPONIA: UM NOVO OLHAR AGRÍCOLA
}

\section{AQUAPONICS: A NEW AGRICULTURAL LOOK}

Talysson Daniel Santos da Silva ${ }^{1}$; Matheus Tenório de Albuquerque Melo ${ }^{2}$; Thales Ramon de Queiroz Bezerra ${ }^{3}$; Ricardo José Araújo Miranda ${ }^{4}$; Willy Vila Nova Pessoa ${ }^{5}$

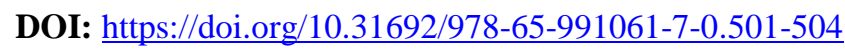

\section{INTRODUÇÃO}

Cada vez mais técnicas de cultivos estão sendo criadas para melhorar os sistemas de agricultura tradicionais, onde o solo é simplesmente um reservatório de nutrientes e um meio de sustentação das plantas.

A aquaponia surge para mudar a forma de produção agricultura tradicional. Aquaponia é a junção de aquicultura (cultivo de peixes) e hidroponia (cultivo de vegetais sem solo, onde as raízes recebem uma solução nutritiva (Rakocy et al. 2006) (Figura 1).

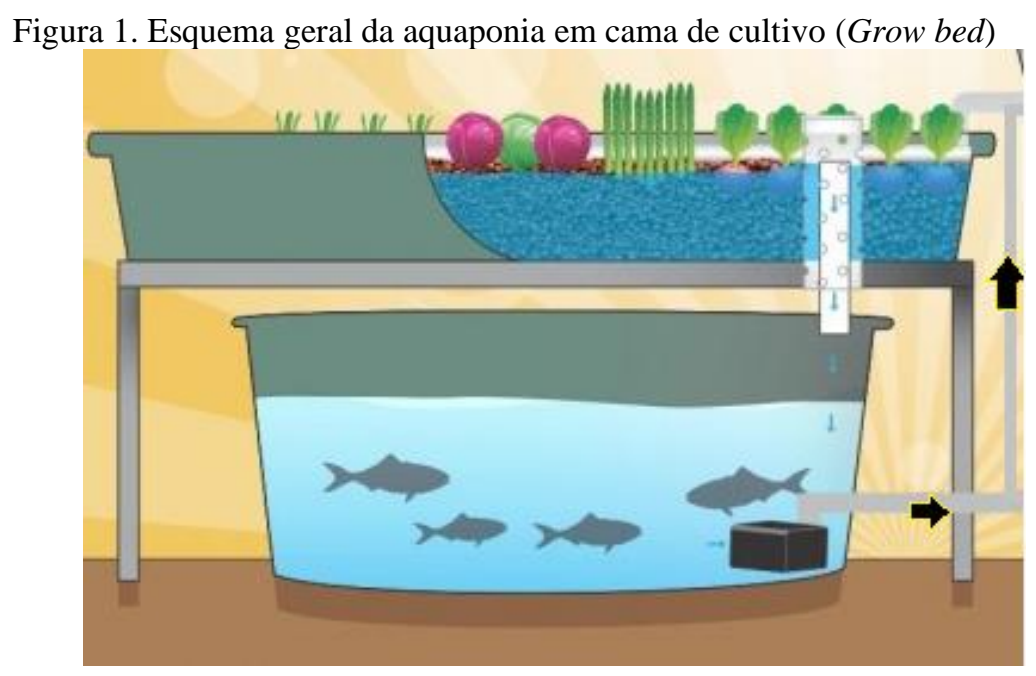

Além disso, os vegetais recebem os nutrientes através bioconversão da matéria orgânica dos peixes e camarões (Carneiro et al. 2015). Os resíduos dos peixes (amônia) são transformados em nitrito e nitrato através de algumas bactérias (nitrossonomas e nitrobacter) que colonizam o biofiltro para a nitrificação (Rakocy et al. 2006; Losordo \& Westerman, 2006).

Os sistemas estão separados e são interligados por um sistema de bombeamento que leva a água rica em matéria orgânica dos peixes para o sistema hidropônico que devolve a

\footnotetext{
${ }^{1}$ Curso Técnico em Agropecuária, IFPE, campus VSA, e-mail: tdanielsantossilva2@gmail.com

${ }^{2}$ Curso Técnico em Agropecuária, IFPE, campus VSA, e-mail: matheusmelosrr@gmail.com

${ }^{3}$ Doutor em Recursos Pesqueiros e Aquicultura, IFPE, campus VSA, e-mail: thalesbezerra@ recife.ifpe.edu.br

${ }^{4}$ Doutor em Engenharia Agrícola, IFPE, campus VSA, e-mail: ricardo.araujo@ vitoria.ifpe.edu.br

${ }^{5}$ Doutor em Recursos Pesqueiros e Aquicultura, IFPE, campus VSA, e-mail: willy.vilanova@ vitoria.ifpe.edu.br
} 
água limpa aos peixes fechando o ciclo de recirculação da água. O cultivo reduz cerca $90 \%$ da água consumida da piscicultura e agricultura convencionais (Losordo \& Westerman, 2006).

Diversas instituições de pesquisa no Brasil têm utilizado minissistemas de aquaponia como recurso didático para participação em feiras, realização de aulas práticas e capacitações a produtores rurais, urbanos e estudantes. A procura pela pesquisa e o aumento do interesse pela aquaponia surgiu recentemente reforçado pela necessidade de obtenção de produtos orgânicos livres de agrotóxicos, herbicidas e pesticidas, de alta qualidade e com baixa incidência de pragas. Sendo, assim foi construído um minissistema aquapônico com o objetivo de difundir a tecnologia de cultivo de peixes e hortaliças em aquaponia, demostrando a importância econômica, social e ambiental dos sistemas integrados de cultivo de hortaliças e peixes.

\section{RELATO DE EXPERIÊNCIA}

Em 14 de setembro de 2018, realizamos uma exposição de aquaponia na feira “EXPOGOITÁ”, com produtores da região de produtos orgânicos organizada pela prefeitura da cidade de Glória de Goitá - PE. Essa iniciativa é pioneira na região uma vez que Vitória de Santo Antão e municípios vizinhos possuem a vocação e a cultura da agricultura orgânica.

A saída do campus VSA para a feira ocorreu por volta das 8:00 horas da manhã, com o suporte de dois veículos: um ônibus para transportar servidores e alunos, e um micro-ônibus escola equipado com projetor, cadeiras e materiais didáticos (mini sistema aquapônico) de acordo com a figura 2.

O mini sistema de aquaponia foi construído para o cultivo em camas com argila expandida (Grow beds) que servira para fixação das plantas (Tomate cereja). A cama de cultivo também serve como um ambiente de ciclagem de nutrientes através das bactérias (nitrosomonas e nitrobacter). As plantas absorvem, como fertilizante orgânico, os nutrientes gerados pelos peixes ornamentais (Betta splendens) no minisistema didático que contém um tanque com capacidade (volume útil) de 50 litros.

Para oxigenação da água, foi utilizado um compressor de ar movido a energia solar (21/min) e uma bomba com vazão máxima de $220 \mathrm{~L} / \mathrm{h}$, altura máxima $50 \mathrm{~cm}$ (coluna) e consumo de 2,5 Watts. 
Figura 2: Mini Sistema didático de aquaponia em cama de cultivo com peixes ornamentais, Betta splendens (Fonte: Própria).

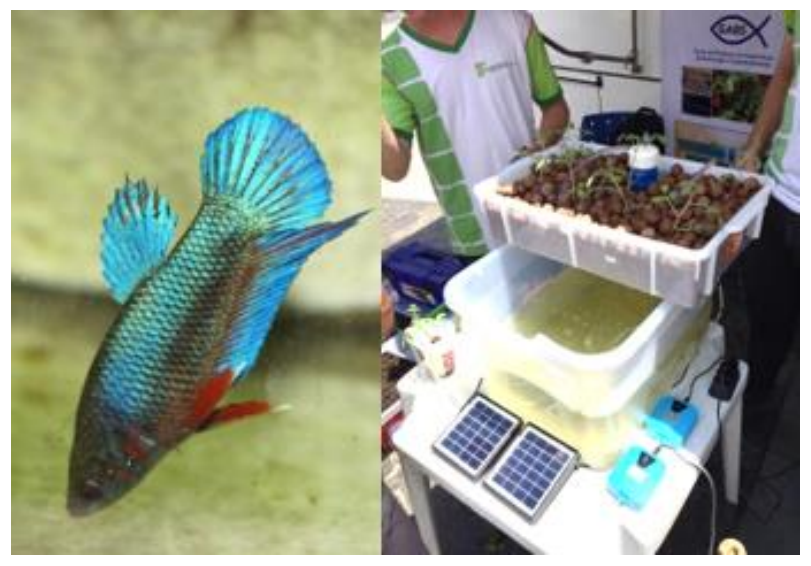

Na cama de cultivo foi instalado um sifão Bell que funciona como uma espécie de descarga na cama de cultivo possibilitando baixar o nível da a água para que as raízes das plantas passem alguns instantes oxigenando evitando o apodrecimento das raízes das mesmas.

Foi muito gratificante poder viver essa experiência, pois pudemos passar conhecimento para o público como também adquirir um pouco mais. No final de cada apresentação observamos que as pessoas aprovaram a aquaponia como sistema de produção, pois, ela possibilita criar peixes (alimento animal) e ao mesmo tempo produzir alimentos vegetais (hortaliças, ervas, frutas), tudo de forma orgânica e de qualidade para o consumo humano.

Durante a feira o público fez diversos questionamentos devido a curiosidade que foi despertada com o minissistema aquapônico (Figura 3). É interessante destacar que mais de 90\% dos visitantes não sabiam do que se tratava a aquaponia. Destaque especial deve ser dado ao compressor de ar movido a luz solar que também despertou a curiosidade para as energias renováveis para o planeta e a diminuição da poluição.

Figura 3. Momento de explicações ao públio sobre a aquaponia (Fonte: Própria)

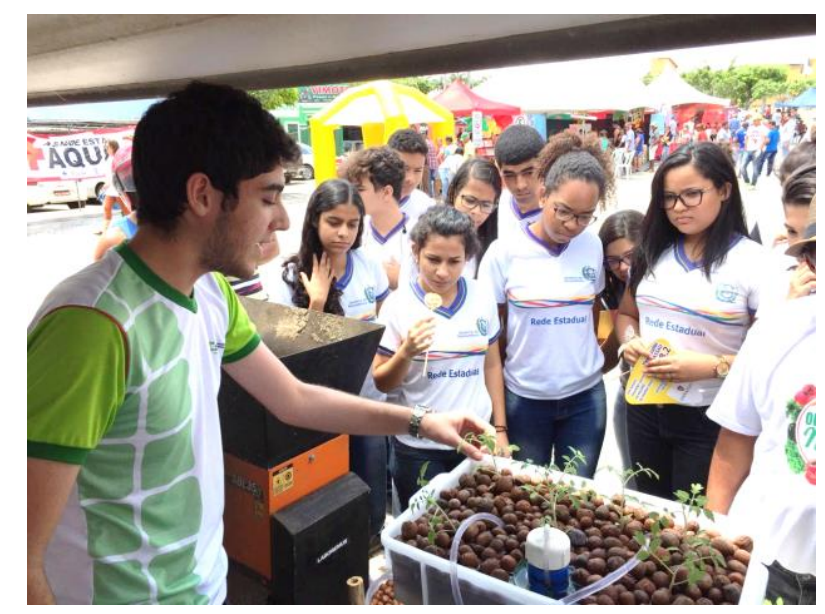




\section{CONSIDERAÇÕES}

A aquaponia possui soluções interessantes tanto para a problemática dos agrotóxicos como no fornecimento de proteína de qualidade a população. A aquaponia pode ser realizada em minissistemas, pequenas áreas e com baixo investimento inicial em sistemas de produção familiar. Adicionalmente, a aquaponia é relatada como uma ferramenta de integração social de comunidades, geração de renda e de qualidade alimentar para as famílias.

Através deste relato de experiência foi possível constatar que a aquaponia pode ser utilizada como ferramenta de educação com a participação da comunidade acadêmica de nível técnico em eventos fora do Instituto Federal de Pernambuco. A participação na "ExpoGoitá 2018 " somente reforçou o potencial da aquaponia como atividade de impacto socioeconômico gerando ganhos em diferentes níveis: educação, produção de alimento saudável e possibilidade de gerar renda para o pequeno produtor rural e urbano.

\section{REFERÊNCIA}

CARNEIRO, P.C.F., MORAIS, C.A.R.S, NUNES, M.U.C., MARIA, A.N., FUJIMOTO, R.Y. Produção integrada de peixes e vegetais em aquaponia. Embrapa Tabuleiros Costeiros, 2015. (Documentos / Embrapa Tabuleiros Costeiros (ISSN 1678-1937, 189). 27 p. 2015.

LOSORDO, T.M.; WESTERMAN. P.W. An analysis of biological, economic, and engineering factors affecting the cost of fish production in recirculating aquaculture systems. Journal of the World Aquaculture Society 25:193-203, 2007.

RAKOCY, J. E.; LOSORDO, T. M.; MASSER. M. P. Recirculating aquaculture tank production systems: Aquaponics - Integrating fish and plant culture. Southern Reg. Aquaculture Center Publications No. 454. 2006. 